\title{
Association Between Methylation Levels of LPL, ADRB3 and MTHFR Genes in Leukocytes from Individuals with Isolated or Associated Morbidities and Inflammation: A Cross-Sectional Study
}

Thais Costa Matte ( $\sim$ thaiscostamatte@gmail.com )

Federal University of Paraiba: Universidade Federal da Paraiba Centro de Ciencias da Saude https://orcid.org/0000-0002-4553-9304

Raquel Patrícia Ataíde Lima

Federal University of Paraiba: Universidade Federal da Paraiba Centro de Ciencias da Saude Rafaella Cristhine Pordeus Luna

Federal University of Paraiba: Universidade Federal da Paraiba Centro de Ciencias da Saude Maria da Conceição Rodrigues Gonçalves

Federal University of Paraiba: Universidade Federal da Paraiba Centro de Ciencias da Saude Flávia Emília Leite de Lima Ferreira

Federal University of Paraiba: Universidade Federal da Paraiba Centro de Ciencias da Saude

Sônia Cristina Pereira de Oliveira Ramalho Diniz

Federal University of Paraiba: Universidade Federal da Paraiba Centro de Ciencias da Saude

Roberto Teixeira de Lima

Federal University of Paraiba: Universidade Federal da Paraiba Centro de Ciencias da Saude

Aléssio Tony Cavalcanti de Almeida

Paraiba Federal University: Universidade Federal da Paraiba

Alexandre Sérgio Silva

Paraiba Federal University: Universidade Federal da Paraiba

Alcides da Silva Diniz

Federal University of Pernambuco: Universidade Federal de Pernambuco

Naila Francis Paulo de Oliveira

Paraiba Federal University: Universidade Federal da Paraiba

Darlene Camati Persuhn

Paraiba Federal University: Universidade Federal da Paraiba

Maria José de Carvalho Costa

Federal University of Paraiba: Universidade Federal da Paraiba Centro de Ciencias da Saude 
Keywords: Epigenetics. DNA methylation. Inflammatory Markers. Chronic Non-Communicable Diseases.

Posted Date: September 17th, 2021

DOI: https://doi.org/10.21203/rs.3.rs-754204/v1

License: (c) (1) This work is licensed under a Creative Commons Attribution 4.0 International License. Read Full License 
$11 *$ thaiscostamatte@gmail.com

\section{Abstract}

14 Epigenetic alterations such as DNA methylation have been associated with the etiology 15 of inflammation-related diseases. The present study evaluated the association between 16 the methylation levels of $L P L, A D R B 3$ and MTHFR genes and the stage of inflammation 17 in individuals with isolated or associated morbidities, as well as in individuals without morbidities. This is a cross-sectional population-based study, in which 261 adults, between 20 and 59 years, individuals of both sex were selected. Inflammatory parameters were evaluated in blood, and the evaluation of methylation levels in the promoter of $L P L$, $A D R B 3$ and MTHFR genes was performed in peripheral blood leukocytes. For statistical treatment, normality analysis was performed using the Lilliefors test, multiple linear regression, in addition to odds ratio. For all tests, the significance level adopted was $5 \%$. In individuals with isolated morbidities, a positive association was observed between CRP values $(2.49 \mathrm{mg} / \mathrm{L} \pm 3.7)$ and $L P L$ gene methylation levels $(35 \% \pm 18)(\mathrm{p}=0.003)$ and 
with associated morbidities, females had higher levels of $L P L$ gene methylation $(40 \% \pm$ 20) $(\mathrm{p}=0.041)$ and for MTHFR gene methylation levels $(35 \% \pm 18)$ a positive association was found with MDA values $(3.02 \mu \mathrm{mol} / \mathrm{L} \pm 0.8)(\mathrm{p}=0.032)$. In addition, the use of medications did not influence the level of methylation for any of the three genes analyzed. Among individuals with isolated or associated morbidities, there was an association between the methylation levels of the $L P L$ gene with the CRP values and females, and furthermore with the MTHFR gene and MDA. This study could help to understand the etiology and treatment of different morbidities, enabling the discovery of new combats resources.

Keywords: Epigenetics. DNA methylation. Inflammatory Markers. Chronic NonCommunicable Diseases.

\section{Background}

The presence of diabetes mellitus, dyslipidemia, hypertension and/or obesity is considered an important indicator of cardiovascular risk, according to the "Strategic Action Plan for Confronting Chronic Non-Communicable Diseases" (CNCDs) of the Ministry of Health of Brazil, with these CNCDs being responsible for the increase in mortality [1].

The epigenetic profile has major potential to better characterize the phenotype of CNCDs, helping to identify individuals at higher risk of developing metabolic complications $[2,3]$. In cardiovascular diseases, gene methylation plays an important role in its pathogenesis [4], and in diabetes mellitus type 1 and 2, epigenetic modifications have been identified as a mechanism by which the environment interacts with the genome and modifies its risk [5]. 
The presence of chronic inflammation is a biological mechanism, related to the development of CNCDs [6]. Inflammation mediates epigenetic changes, resulting in multiple signaling pathways that culminate in the activation of gene transcription. In contrast, gene transcription factors and other proteins form transcription complexes that regulate the expression of some genes involved in the inflammatory process $[7,8]$.

The lipoprotein lipase $(L P L)$ gene is responsible for encoding a lipoprotein with the same name and is located on chromosome 8q22 [9]. The LPL enzyme has a central role in lipid metabolism, as it works by hydrolyzing lipoproteins rich in triglycerides that are available for energy needs and for storage in the adipose tissue $[10,11]$. The increase in $L P L$ methylation levels in leukocytes was correlated with dyslipidemic changes, such as lower levels of high-density lipoprotein (HDL) and higher levels of low-density lipoprotein (LDL) [12], increasing the risk of cardiovascular disease, obesity and insulin resistance $[13,14]$.

The $\beta 3$ adrenergic receptor gene $(A D R B 3)$ is located on chromosome 8 [15] and encodes a receptor protein that is a member of the adrenergic receptor family [16] that is mainly expressed in brown, beige and white adipocytes. Activation of the enzyme acts by stimulating brown adipocytes and accelerating the utilization of beige adipocytes, as well as stimulating glucose uptake $[17,18]$. Methylation in the $A D R B 3$ gene in leukocytes has been related to dyslipidemia [19], likewise being a causal factor in the alteration of the waist-hip ratio and alterations in blood pressure in obese individuals [20].

The methylenetetrahydrofolate reductase $(M T H F R)$ gene exerts an important influence on the DNA methylation process and is located on chromosome 1 (1p26.3) [21]. Its role is due to its participation in the production of folate. The folate and methionine cycles together participate in the so-called "one carbon metabolism" which consists of a set of interconnected pathways that provide methyl groups to make methyl available for 
methylation [21, 22]. Changes in their methylation levels analyzed in leukocytes are related to the pathophysiology of diabetes and its chronic complications [23, 24], likewise cardiovascular disease and cancer [24, 25].

Studies regarding the influence of more than one gene with inflammatory variables on different associated morbidities presence in the same individual are still scarce, even though this is the most common form of disease prevalence in populational studies. Therefore, this study could help to elucidate the genes roles and mechanisms played on CNCDs, along with discovering innovative methods to overcome them, through the evaluation of relationships among methylation levels of the LPL, ADRB3 and MTHFR genes in a human-based population with different levels of morbidities and inflammation.

\section{Methods}

\section{Study design}

Cross-sectional population-based study linked to a population-based survey entitled "II Cycle of Diagnosis and Intervention of the Most Prevalent Food, Nutritional and Non-Communicable Diseases of the Population in the Municipality of João Pessoa/PB" (II Ciclo de Diagnóstico e Intervenção da Situação Alimentar, Nutricional e das Doenças não Transmissíveis mais Prevalentes da População do Município de João Pessoa/PB - II DISANDNT/Paraíba)", carried out from May 2015 to May 2016. It was funded by FAPESQ/MS/CNPQ [26].

The research protocol was approved by the Research Ethics Committee at the Health Sciences Center (Centro de Ciências da Saúde - CCS) of the Federal University of Paraíba (Universidade Federal da Paraíba, UFPB), under the protocol number 
100 0559/2013. Research participants signed the informed consent form (ICF), in accordance

101 with the ethical standards of research involving human beings.

102

103 Population and Sampling

$104 \quad$ Males and females adults aged between 20 and 59 years old from different

105 socioeconomic conditions, residing in the East and West zones of the city of João Pessoa

106 were selected to participate in the survey. Individuals previously diagnosed with any

107 neuropsychiatric disorders; users of anorectics or anabolic steroids; pregnant women or

108 children were prevented to take part in the project.

109 The sample was calculated based on previous similar studies $[27,28]$ along with

110 a single sampling procedure, consisting of several levels according to the data available

111 from the City Council, such as the city map, number of blocks per neighborhood, and

112 data from the Brazilian Institute of Geography and Statistics (Instituto Brasileiro de

113 Geografia e Estatística, IBGE) [29].

114 At a first level, a stratified sampling over the blocks [30] was used, given the

115 heterogeneity of the variable income and the association between income, disease

116 prevalence, and nutrition. Neighborhoods were classified by income class into 4 strata,

117 based on the map of city blocks. After stratification, the number of representative blocks

118 per zone was calculated [30]. A formula was used to obtain the weight of each stratum

119 and another to calculate the sample per zone [31].

120 Therefore, the total number of neighborhoods visited, corresponding to the East

121 and West zones of the municipality of João Pessoa was 24, with an estimate of visits

122 carried out in 105 blocks. After defining the number of blocks per neighborhood, they

123 were drawn by lot. The selected block served as a reference for the selection of visited 
124 households. Thus, the number of samples in this study totaled 261 individuals. The 125 significance utilized was 0.05 .

\section{Data collection}

128 The home visits and the survey were carried out by undergraduate students of the

129 Nutrition Program and Master's and PhD candidates of the Postgraduate Program in

130 Nutrition Sciences (Programa de Pós-graduação em Ciências da Nutrição, PPGCN) of the

131 UFPB. All the selected households that were within the age group and wanted to

132 participate in the research have participated of the data collection. Demographic and

133 epidemiological characterization questionnaires were applied. Participants were asked

134 about the diagnosis and use of medications used to treat diseases: hypertension, diabetes,

135 obesity, cardiovascular disease, and dyslipidemia etc. After data collection, the

136 population was divided into three categories: (1) group without morbidities (individuals

137 without a diagnosis of morbidity, $n=67$ ); (2) group with isolated morbidities (individuals

138 diagnosed with at least one morbidity, $n=114$ ); (3) group with associated morbidities

139 (individuals diagnosed with at least two morbidities, $\mathrm{n}=80$ ).

141 Nutritional assessment

142 Triplicate measurements of weight and height were done, whereupon the mean 143 was utilized to classify the participants according to the Body Mass Index (BMI) charts, 144 under the World Health Organization (WHO) parameters [32].

146 Sample collection

147 Households that had completed the third 24-hour recall were visited by an 148 experienced nurse that performed peripheral blood sample collections. The participants 
149 were required to do a 12-hours fasting before the procedure was done. Two sterile vacuum

150 tubes ( $4 \mathrm{ml})$ were used, one for serum analysis (containing clot activator) and the other for

151 plasma analysis (with EDTA anticoagulant), including DNA methylation analysis. To

152 ensure the effectiveness of the procedure, a follow-up was conducted, whereby the

153 households were called by the team twice: to schedule the examination and guidance

154 needs; and to confirm and reinforce the guidelines. The samples were kept at $-20^{\circ} \mathrm{C}$ until

155 the biochemical analysis and DNA methylation profile were performed.

DNA Methylation Level Analysis

The methylation levels in the promoter of the ADRB3, MTHFR and $L P L$ genes were evaluated using the HRM (High Resolution Melting) technique with the aid of the

160 Applied Biosystems 7500 Fast System Real Time Thermocycler. For that, the DNA 161 previously extracted according to Oliveira et al. [27] was quantified by fluorescence 162 (QubitTM), had its purity checked by a Nanodrop ® spectrophotometer (Thermo 163 Scientific, California, USA) and kept at $-20^{\circ} \mathrm{C}$ until the analysis. Afterwards, the samples 164 were submitted to DNA conversion by bisulfite from the Cells-to-CpG ${ }^{\mathrm{TM}}$ conversion kit 165 (Applied Biosystems, Life Technologies, California), according to the manufacturer's instructions. The primers as well as the CRP conditions used were performed as 167 previously described [33]. To calculate methylation levels, commercially available bisulfite-converted

169 control DNAs were purchased as CpGenome positive (100\% methylated) and negative 170 control (0\% methylated) (Chemicon, Milipore, Billerica, MA, USA). We performed the 171 appropriate dilutions to obtain the following ratios: 0, 25, 50, 75 and 100\%; all samples 172 were run in triplicate to acquire the standard curves and compare with the melting profile 173 of the samples. 


\section{Statistical analysis}

All statistical analyzes were performed utilizing the STATA 13 software [34].

177 Initially, normality test was performed using the Lilliefors test. To identify the existence

178 of a significant association between the different levels of methylation of $L P L$, ADBR3

179 and MTHFR genes, amongst individuals without morbidities, with isolated or associated

180 morbidities, a multiple linear regression model was performed. Finally, the odds ratio was

181 evaluated, in order to assess the association of medicine intake and the methylation levels

182 of the studied genes. For all tests, the significance level assumed was 5\%.

183

184 Results

185 Amongst the 261 participants aged between 20 and 59 years, there was a

186 predominance of females (66.8\%). Descriptive data regarding age, sex, BMI, and

187 medication use is demonstrated in Table 1.

188

189 Table 1 General characteristics of the adult individuals

\begin{tabular}{|c|c|c|c|}
\hline & $\begin{array}{c}\text { NO MORBIDITIES } \\
(n=67)\end{array}$ & $\begin{array}{c}\text { WITH ISOLATED } \\
\text { MORBIDITIES } \\
(n=114)\end{array}$ & $\begin{array}{c}\text { WITH ASSOCIATED } \\
\text { MORBIDITIES } \\
(\mathbf{n}=\mathbf{8 0})\end{array}$ \\
\hline Age & 32.4 & 37.4 & 37.4 \\
\hline Female & $\mathrm{n}=46(68.65 \%)$ & $\mathrm{n}=69(60.5 \%)$ & $\mathrm{n}=60(74.1 \%)$ \\
\hline Male & $\mathrm{n}=21(31.34 \%)$ & $\mathrm{n}=45(39.5 \%)$ & $\mathrm{n}=21(25.9 \%)$ \\
\hline BMI (kg/m²) & 21.67 & 27.14 & 28.83 \\
\hline \multicolumn{4}{|l|}{ Medicine } \\
\hline No & $\mathrm{n}=60(89.55 \%)$ & $\mathrm{n}=87(76.32 \%)$ & $\mathrm{n}=24(30 \%)$ \\
\hline Yes & $\mathrm{n}=07(10.45 \%)$ & $\mathrm{n}=27(23.68 \%)$ & $\mathrm{n}=56(70 \%)$ \\
\hline
\end{tabular}

Among individuals with isolated morbidities, stood out those who were overweight (overweight or obese)

$19168.42 \%$ and hypertension with 6.14\%. In individuals with associated morbidities, $38.75 \%$ were overweight

192 and had hypertension, $17.5 \%$ were overweight and had respiratory system diseases, $13.75 \%$ were 193 overweight and had diabetes, $13.75 \%$ were overweight and had rheumatic diseases and $8.75 \%$ overweight 194 and had dyslipidemia. Only $32.5 \%$ of individuals had 3 or more morbidities.

195 
Regarding the methylation levels of the $L P L, A D R B 3$ and MTHFR genes, and the

197 levels of inflammatory markers in the population studied, no statistically significant

198 differences were found between the groups (Table 2). The mean methylation levels

199 between groups ranged between $35-40 \%$ for the $L P L$ gene, $40-44 \%$ for the ADRB3 gene

200 and $33-35 \%$ for the MTHFR gene ( $>>0.05$ ). Regarding the inflammatory parameters, the

201 means were within the reference values in all groups.

202

Table 2 Methylation levels of $L P L, A D R B 3$ and MTHFR genes, and inflammatory markers

\begin{tabular}{cccccccc}
\hline & \multicolumn{2}{c}{ NO } & WITH ISOLATED & \multicolumn{2}{c}{ WITH } \\
& \multicolumn{2}{c}{ MORBIDITIES } & \multicolumn{2}{c}{ MORBIDITIES } & $\begin{array}{c}\text { ASSOCIATED } \\
\text { MORBIDITIES }\end{array}$ & \\
\hline & MEAN & SD & MEAN & SD & MEAN & SD & P value \\
\hline LPL GENE (\%) & 35 & 16 & 35 & 18 & 40 & 20 & $\mathrm{p}=0.2081$ \\
ADRB3 GENE (\%) & 44 & 20 & 41 & 18 & 40 & 17 & $\mathrm{p}=0.4311$ \\
MTHFR GENE (\%) & 33 & 16 & 35 & 18 & 35 & 18 & $\mathrm{p}=0.8664$ \\
TAC (\%) & 40 & 0.13 & 42 & 0.15 & 40 & 0.14 & $\mathrm{p}=0.6091$ \\
MDA ( $\boldsymbol{\mu m o l} / \mathbf{L})$ & 2.8 & 1.03 & 2.77 & 0.83 & 3.02 & 0.80 & $\mathrm{p}=0.0509$ \\
CRP (mg/L) & 2.29 & 3.09 & 2.49 & 3.7 & 2.58 & 3.25 & $\mathrm{p}=0.8742$ \\
AGP $(\mathbf{m g} / \mathbf{d L})$ & 63.25 & 22.31 & 65.99 & 17.59 & 65.16 & 17.7 & $\mathrm{p}=0.6423$ \\
\hline
\end{tabular}

204

SD: Standard deviation.

205

206

Table 3 presents a multiple regression analysis between methylation levels of the

207 studied genes and inflammatory markers, when the model was adjusted for sex and age.

208 We observed that in individuals without morbidities $(n=67)$ no significant association was

209 found between the methylation levels of selected genes and the inflammatory parameters.

210 In individuals with isolated morbidities $(n=114)$, we found that when CRP increases by 1

211 (mg/L) the methylation levels of the $L P L$ gene increase by 0.0139 , showing a statistical

212 difference $(p=0.003)$. 
215 Table 3: Association between methylation levels of $L P L, A D R B 3$ and MTHFR genes and inflammatory

216 markers

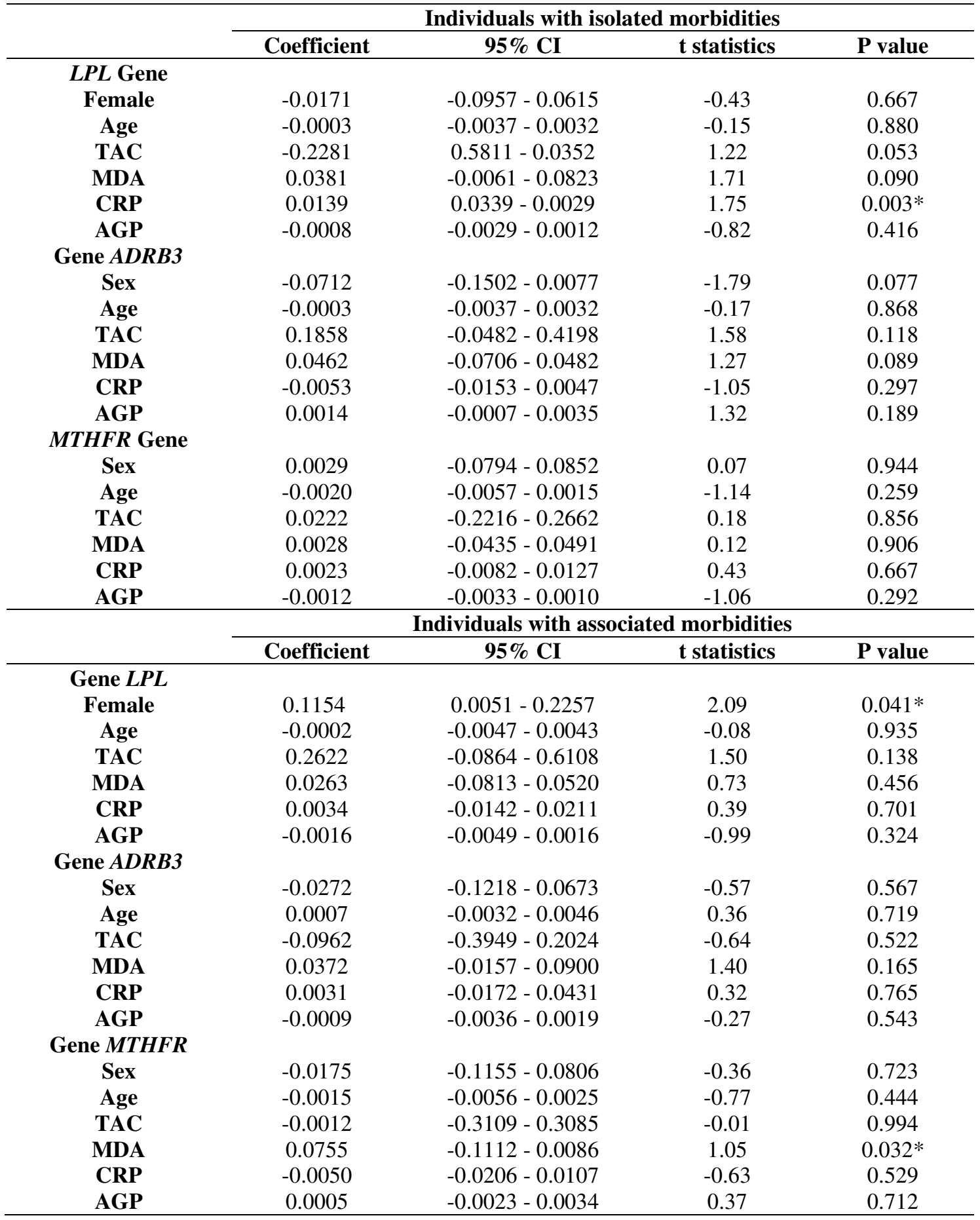

217 In this model, the following variables were included: lipid profile, homocysteine and folic acid, but no

218 association was found with the methylation of the respective genes studied. Analyzes were also performed

219 in individuals without morbidities, however, no significant results were found.

Among individuals with associated morbidities $(\mathrm{n}=80)$, females had higher levels

222 of $L P L$ gene methylation with an increase of 0.1154 , with a statistical difference

223 ( $\mathrm{p}=0.041)$. In this same population for the MTHFR gene, we found that as the MDA 
224 increases by $1 \mu \mathrm{mol} / \mathrm{L}$, the gene methylation levels increase by 0.0755 , with a significant 225 statistical difference $(\mathrm{p}=0.032)$.

In table 4, a simple linear regression was performed analyzing the odds ratio for

227 the association of use of medications with the levels of methylation of the genes studied.

228 No significant differences were found in any of the groups when subdivided by the 229 number of presented morbidities, and it was observed that the use of medications did not 230 influence the level of methylation for any of the three genes analyzed in individuals 231 without morbidities and with isolated or associated morbidities.

232

233

234

Table 4 Medication usage and methylation levels of $L P L, A D R B 3$ and $M T H F R$ genes

\begin{tabular}{lcccc}
\hline Medication & \multicolumn{4}{c}{ Individuals without morbidities } \\
\cline { 2 - 5 } usage & Odds Ratio & $\mathbf{9 5 \%}$ IC & Std. Err. & P value \\
\hline Gene $A D R B 3$ & 0.6077 & $0.1112-3.3209$ & 0.5266 & 0.565 \\
Gene MTHFR & 1.1904 & $0.2137-6.6330$ & 1.0433 & 0.842 \\
\hline Medication & \multicolumn{4}{c}{ Individuals with isolated morbidities } \\
usage & Odds Ratio & $\mathbf{9 5 \%}$ IC & Std. Err. & P value \\
\hline LPL Gene & 2.0794 & $0.8218-5.2616$ & 0.9849 & 0.122 \\
ADRB3 Gene & 0.9865 & $0.3953-1.4619$ & 0.4603 & 0.977 \\
MTHFR Gene & 0.8695 & $0.3499-2.1606$ & 0.4038 & 0.763 \\
\hline Medication & \multicolumn{5}{c}{ Individuals with associated morbidities } \\
usage & Odds Ratio & $\mathbf{9 5 \%}$ IC & Std. Err. & P value \\
\hline LPL Gene & 0.8543 & 0.3243 & 0.4222 & 0.750 \\
ADRB3 Gene & 0.7315 & 0.2808 & 0.3574 & 0.522 \\
MTHFR Gene & 0.7623 & 0.2910 & 0.3745 & 0.581 \\
\hline
\end{tabular}

235

236

237

Discussion

The $L P L, A D R B 3$ and MTHFR genes that encode lipase, beta-adrenergic receptor

239 and methylenetetrahydrofolate reductase proteins, respectively, are genes that are

240 associated with the state of inflammation characteristic of morbidities [13, 14, 19, 21],

241 and for this reason they were selected for the present study, which aimed to analyze their

242 methylation profile, alongside inflammatory parameters in individuals without

243 morbidities and with isolated or associated morbidities, and to evaluate their associations. 
It was observed that the methylation levels of the three genes studied were similar between the groups, indicating that there are no alterations in the methylation profile in

246 the $\mathrm{CpG}$ sites studied when considering individuals with or without morbidities.

247 Likewise, inflammatory and antioxidant parameters were similar between groups.

248 One of the possible justifications for these results is that, as it is data from

249 individuals who are not in a hospital environment (being compensated for the evolution

250 of the disease due to the use of medications or change in lifestyle), they did not present 251 changes in the methylation profile.

In a study evaluating the epigenome of DNA samples from whole blood in critically ill patients, 668 differentially methylated regions were found between septic and non-septic patients. There was a predominance of hypermethylated sites (61\%), compared to hypomethylated sites (39\%) in septic patients. However, none of the genes mentioned in the study coincide with those worked in this research [35]. When analyzing the methylation in the $A B O$ and $A G T R 1$ genes in hospitalized patients, positive associations were found between their hypermethylation and cardiovascular disease, however, this association with AGTRl was only found in men [36, 37].

In addition, despite being within the reference value, CRP was in the upper tertile

261 (>2mg/dL), which may indicate an inflammatory change in the body [38]. CRP is an acute-phase inflammatory protein extensively used worldwide as a biomarker of 263 inflammation, infection and/or cardiovascular events [39]. Evidence suggests that it is not 264 only a marker of inflammation but also plays an active role in the inflammatory process 265 [40]. However, lifestyle factors including smoking, sex, age, and BMI, in addition to changes in lipid levels and blood pressure can also act by changing their levels in the body 
According to the results shown in Table 3, adults who were not diagnosed with morbidity did not show any association between the lipid profile, the measured inflammatory markers nor the methylation levels of the LPL, ADRB3 and MTHFR genes. with isolated morbidities and CRP, has shown a significant association $(\mathrm{p}=0.003)$,

273 indicating that when CRP values were higher, $L P L$ gene methylation levels increased by individuals with isolated morbidities. It suggests that the increase in $L P L$ methylation levels could lead to a decrease in lipoprotein lipase glycoprotein synthesis. An association was found between increased levels of methylation in promoters of this gene in subcutaneous adipose tissue and a reduction in $L P L$ expression [42]. Although the interpretation of gene methylation studies is difficult to interpret, given the multiple differences in methylation patterns at $\mathrm{CpG}$ sites in different cells and tissues [43]. The LPL enzyme is related to the transport pathways of lipid metabolism $[10,11]$. Because it works by hydrolyzing triglyceride-rich lipoproteins, the reduction in its functioning increases the risk of developing some diseases such as metabolic syndrome [44], insulin resistance [14, 11], dyslipidemia and obesity [13].

It was observed that the CRP level was associated with hypermethylation or hypomethylation in a variety of genes such as genes encoding inflammatory markers such as IL-6, TGFA, CXCL3, CXCL11, CXCL23, etc. [45]. However, it is still unknown whether changes in the methylation profile act as a causal factor or consequence of the inflammatory state. In a study using the GWAS and EWAS techniques, no associations were found between PCR values for DNA methylation. However, when performing the causal effect test of DNA methylation on PCR, the increase in methylation of TMEM49, BCL3 and MIR21 genes showed associations with PCR levels. These results suggested that the association of methylation profile with PCR is more likely to be influenced by 
293

294

295

296

297

298

299

300

301

302

303

304

305

306

307

308

309

310

311

312

313

316

317

causal factors of DNA methylation rather than the opposite [46]. No studies were found that made the association between the levels of methylation of the $L P L$ gene with the serum levels of CRP, and the present study is innovative in bringing this association.

In individuals with associated morbidities, females were significantly associated with the level of methylation of the $L P L$ gene. That is, when the individual is female, the methylation level of the $L P L$ gene increases by $0.11 \%$. Scholars point out that women may have higher levels of methylation in their genomes compared to men, indicating a possible difference in methylation between the sex [47].

In a study analyzing the sex association in the methylation of CpG sites, 12,177

CpG sites showed significant differences in methylation between women and men. In autosomal chromosomes, the differences in methylation between the sex were $46.1 \%$, with greater methylation in women compared to men, a pattern also observed when analyzing the methylation profiles of the $\mathrm{X}$ chromosome [48]. These data are consistent with the systematic review study in which 31 genetic loci were associated with sex differences in cardiometabolic diseases and men in general had lower levels of methylation in their genome [49].

A factor that enables so many divergences in this profile is due to hormonal changes that exist between sex, especially in sex hormones. These, in turn, can directly regulate the DNA, in addition to modulating the epigenetic profile differently in each of the sex [50]. Sex-specific associations were observed in CpG sites, in a study in which methylation in the $L P L$ gene had negative associations with glucose only in women [51]. In individuals with associated morbidities, MDA also showed a significant association $(\mathrm{p}=0.032$ ), but with the MTHFR gene, indicating that when the MDA increases, the level of methylation of the MTHFR gene also increases and, consequently, leading to a reduction in expression of the MTHFR gene [52]. Unlike the present study, 
318 other authors did not find significant associations between the MTHFR gene methylation

319 profile in leukocytes and serum MDA levels [24]. However, studies associating MTHFR and MDA methylation remain scarce.

Studies involving other genes have shown significant results in this association,

322 the increase in $M L H$ and IFNAR methylation levels were positively related to MDA

323 marker levels [53, 54]. Higher levels of MDA are related to increased levels of lipid

324 peroxidation in cells [55] and because it is generated during oxidative stress, it can be detected in plasma and different tissues of patients suffering from a wide range of diseases $[55,56,57]$.

Long-term oxidative stress is known to lead to chronic alterations in enzyme, transcriptional, epigenetic and genomic regulation. The formation of reactive oxygen species promotes cell proliferation by changing metabolic and cell control mechanisms, causing DNA damage, genomic instability, and inflammation. Thus, the increase in MDA is also involved in cell signaling and the formation of DNA adducts, which have the ability to affect chromatin modifications $[53,51]$. Furthermore, important effects have been identified in different types of immune system cells indicating that MDA may be

334 biologically active as a mediator not only of oxidative stress, but also of inflammation [58].

Genetic variations of genes involved in the metabolism of a carbon can lead to 337 dysregulation of DNA methylation patterns, for example, the MTR and MTHFR genes

338 [6]. Furthermore, an abnormal performance of MTHFR can lead to metabolic 339 disturbances through changes in homocysteine levels, for example, MTHFR deficiency 340 can result in hyperhomocysteinemia [59]. Associations between MTHFR methylation and 341 increased HCY levels are frequently observed, and studies point to HCY as a potent risk 
342 factor for oxidative stress, in addition to several other mechanisms that lead to the

343 development of cardiovascular diseases [21].

344 Additionally, there is possibly a compensation when HCY is elevated, leading to

345 demethylation of MTHFR in the blood in order to increase the expression of the MTHF

346 enzyme and increase the conversion of homocysteine into methionine [60]. In that

347 mentioned study, this picture was evident in patients with clinical diabetic nephropathy,

348 who presented high levels of homocysteine, together with demethylated gene profiles.

349 In the present study, although there was no difference between the methylation

350 levels of the MTHFR gene and the mean values of homocysteine in the groups, it was

351 found that approximately one third of the sample per group (no morbidities $29.85 \%$, with

352 isolated morbidities $36,84 \%$ and with associated morbidities $29.6 \%$ ) had moderately high

353 levels of homocysteine (results not demonstrated). Probably these high results in

354 homocysteine did not influence the levels of methylation of the gene as they were

355 homogeneously distributed in the three groups. One of the possible justifications for the

356 group without morbidities to also present an increase in serum homocysteine levels,

357 would be due to the use of birth control medications, the contraceptives [61, 62].

358 The ADRB3 gene was not significantly associated with any of the studied

359 variables. Furthermore, no significant changes were found regarding its methylation

360 profile. More methylated profiles of $A D R B 3$ are commonly found in obese individuals,

361 due to their participation in the regulation of body weight [15]. However, the present

362 study had a greater number of eutrophic individuals (43.5\%), when compared to obese

363 individuals (20.2\%), which may have influenced the results found regarding the 364 methylation profile of this gene.

365 Alterations in the $A D R B 3$ gene have an influence on metabolic and lipid disorders

366 [63]. ADRB3 hypermethylation in adipose tissue of obese individuals has been linked to 
367

368

369

370

371

372

373

374

375

376

377

378

379

380

381

382

383

384

385

386

387

388

389

390

a greater susceptibility to visceral obesity and alteration in body fat distribution [64] and methylation in the promoter of the $A D R B 3$ gene in visceral adipose tissue has been linked as a causal factor in the alteration waist-hip ratio, as well as the change in blood pressure in obese individuals [20].

Table 4 shows that the use of medication was not considered a factor influencing the methylation profile for any of the three genes analyzed in individuals with isolated or associated morbidities. It is necessary to highlight that among the 67 individuals without diagnosed diseases, $14(20.9 \%)$ were using medication and/or supplements, with nutritional supplements rich in proteins or contraceptives being the most used. Because of this, the multiple regression analysis at first was performed by inserting the group without morbidities using these substances and at the second moment this group was not compared to the others, keeping the result described previously.

Based on the literature, it was expected that individuals with isolated or associated morbidities using medications would present alterations in the levels of methylation in leukocytes, when compared to individuals without morbidities. It is believed that medications have an influence on epigenetic processes and that this influence may justify the beneficial and/or deleterious effects attributed to the use of medications [65].

Among the main medications used in the treatment of diabetes, metformin stands out. This medication has been shown to act in multiple actions in epigenetic regulation and its effects on DNA methylation include increasing and decreasing the methylation profile in promoters of different genes $[66,67]$. One of the possible mechanisms by which metformin influences DNA methylation includes modulation of the activity of DNA methyltransferases (DNMT). It is known that while AMPK directly inhibits DNMT activity, metformin can indirectly reduce the endogenous activity of DNMT inhibitors. 
391 However, the general effect of metformin on DNA methylation and gene expression is

392 not fully understood [67].

393 To control plasma cholesterol levels, statin is one of the most prescribed

394 medications. However, it has been observed to contribute to the increased risk of diabetes

395 and the mechanism that involves this process remains unclear [68]. The $A B C G 1, A B C A 1$

396 and ACSL3 genes were inversely associated with the use of statins, methylation in CpG

397 islands and diabetic markers under study. These genes stood out for being involved in

398 cholesterol metabolism and glycemic pathways [68]. There are also reports of epigenetic

399 effects of angiotensin receptor blocking medications such as Enalapril, Lisinopril and

400 Captopril. Furthermore, Losartan was shown to be able to reverse the hypomethylation

401 of the AT1 promoter, assuming that the effects of Losartan on blood pressure and

402 proteinuria probably represent epigenetic processes [69].

403 No studies on the absence of changes in DNA methylation levels related to the 404 use of medication were found in the consulted literature. Possibly, the absence of changes 405 in the levels of DNA methylation related to the use of medications found in the present 406 study may have been found because it is a population-based study, in which different 407 medications were used in different pathologies.

408 In addition, these results may have been influenced by the responses of the 409 participants, as $76.31 \%$ of the individuals with a medical diagnosis of one morbidity and $41030 \%$ with a medical diagnosis of two or more morbidities were not taking medications. 411 On the other hand, individuals who had no medical diagnosis of any morbidity, $10.45 \%$ 412 were already using medications (data presented in table 1).

413 It is observed that there are few articles that associate PCR and MDA markers 414 with the studied genes. Therefore, the present study presents itself as a pioneer in better 415 understanding the metabolic processes involving these markers and the $L P L, A D R B 3$ and 
416 MTHFR genes. The understanding of these processes is of fundamental importance both

417 in the treatment of diseases, as well as in discovering new combat strategies, and the

418 results should be analyzed together with the results of other epigenetic and genetic 419 analyses.

420 As for the limitations and strengths of the study, the absence of studies on the 421 association between methylation levels of $L P L, A D R B 3$ and MTHFR genes with isolated 422 and associated morbidities and inflammation are considered strong points. As limitations 423 of the study, the lack of gene expression analysis is pointed out.

\section{Conclusion}

In individuals without morbidities, no associations were observed between the methylation levels of selected genes and inflammatory parameters. In individuals with isolated morbidities, a positive association was observed between CRP values and $L P L$ gene methylation levels, and in individuals with associated morbidities, female individuals had higher levels of $L P L$ gene methylation. In this same population, for the methylation levels of the MTHFR gene, a positive association was found with the MDA values and finally it was observed that the use of drugs was not considered a factor influencing the methylation levels of the three genes analyzed in individuals with morbidities.

\section{Abbreviations}

437 ADRB3: $\beta 3$ adrenergic receptor; AGP: Alpha-1-acid glycoprotein; TAC: Total antioxidant capacity; CCS: Health Sciences Center; CNCD: Chronic Noncommunicable Diseases; DNMT: DNA methyltransferases; HCY: Homocysteine; HDL: High Density 440 Lipoprotein; HRM: High Resolution Melting; IBGE: Brazilian Institute of Geography 441 and Statistics; II DISANDNT/PB: II Cycle of Diagnosis and Intervention of the Food, 
442 Nutritional and Non-Communicable Diseases Most Prevalent in the Population of João

443 Pessoa/PB; BMI: Body Mass Index; LDL: Low Density Lipoprotein; LEFTADS:

444 Laboratory for the Study of Physical Training Applied to Performance and Health; LPL:

445 Lipoprotein lipase; MDA: Malondealdehyde; MTHFR: Methylenetetrahydrofolate

446 reductase; CRP: C-reactive protein; TBARS: Thiobarbituric Acid; FICF: Free and

447 Informed Consent Term; UFPB: Federal University of Paraíba.

448

449 Ethics approval and consent to participate

450 The study was approved by the Research Ethics Committee of the CCS/UFPB,

451 under the Protocol Number 0569/15.

452

453 Consent for publication

$454 \quad$ Not applicable.

455

Availability of data and materials

457

The datasets used and/or analyzed during this study are available from the

corresponding author upon reasonable request.

459

460

Competing interests

461

The authors declare that they have no competing interests.

462

$463 \quad$ Funding

464

Funded by FAPESQ/MS/CNPQ.

465

466 Authors' contributions 
468 Paulo de Oliveira, Maria da Conceição Rodrigues Goncalves, Sônia Cristina Pereira de 469 Oliveira Ramalho Diniz, Darlene Camati Persuhn, Maria José de Carvalho Costa. Project 470 Administration: Rafaella Cristhine Pordeus Luna, Alcides da Silva Diniz, Darlene Camati 471 Persuhn, Maria José de Carvalho Costa. Methodology: Thais Costa Matte, Raquel Patrícia 472 Ataíde Lima, Rafaella Cristhine Pordeus Luna, Alcides da Silva Diniz, Aléssio Tony 473 Cavalcanti de Almeida, Flávia Emília Leite de Lima Ferreira. Formal Analysis: Thais 474 Costa Matte, Raquel Patrícia Ataíde Lima, Aléssio Tony Cavalcanti de Almeida, Roberto 475 Teixeira de Lima, Alexandre Sergio Silva, Maria José de Carvalho Costa. Software: 476 Flávia Emília Leite de Lima Ferreira, Alexandre Sergio Silva.

\section{Acknowledgments}

We would like to thank the project coordinator, Professor Doctor Maria José de 480 Carvalho Costa, as well as her entire team that made this study possible, along with the 481 Graduate Program in Nutrition Sciences at the Federal University of Paraíba.

\section{Authors details}

1 Department of Nutrition, Health Sciences Center, Federal University of Paraíba for Applied Social Sciences, Federal University of Paraíba (UFPB), João Pessoa, Paraíba, 58000-000, Brazil. 3 Department of Nutrition, Health Sciences Center, Federal University 488 of Pernambuco (UFPE), Recife, Várzea, 50000-000, Brazil. 4 Department of Molecular Biology, Center for Exact Sciences and Natural Sciences, Federal University of Paraíba (UFPB), João Pessoa, Paraíba, 58000-000, Brazil. 


\section{References}

493

4941 Violan C, Foguet-Boreu Q, Flores-Mateo G, Salisbury C, Blom J, Freitag M, Glynn L, 495 Muth C, Valderas JM. Prevalence, Determinants and Patterns of Multimorbidity in Primary Care: A Systematic Review of Observational Studies. Plos One, 2014;9:1-9.

497

498

2 Guénard F, Tchernof A, Deshaies Y, Pérusse L, Biron S, Lescelleur O, Biertho L, 499 Marceau S, Vohl M. Differential methylation in visceral adipose tissue of obese men discordant for metabolic disturbances. Physiol genomics, 2014;46:216-222.

501

5023 Keller M, Kralisch S, Rohde K, Shleinitz D, Dietrich A, Shon MR, Gartner D,

503 Lohmann T, DreBler M, Tonjes A, Stumvoll M, Kovacs P, Fasshauer M, Bluher M,

504 Bottcher Y. Global DNA methylation levels in human adipose tissue are related to fat

505 distribution and glucose homeostasis. Diabetologia, 2014;57:2374-2383.

506

5074 Zhang Y, Zeng C. Role of DNA methylation in cardiovascular diseases. Clin. Exp.

508 Hypertens, 2016;38:261-267.

509

5105 Bansal A, Pinney SA. DNA methylation and its role in the pathogenesis of diabetes.

511 Pediatr Diabetes, 2017;18:167-177.

512

5136 Gogna P, O’Sullivan, DE, King WD. The effect of inflammation-related lifestyle

514 exposures and interactions with gene variants on long interspersed nuclear element-1

515 DNA methylation. Epigenomics, 2018;10:1-12. 
5177 Stylianou E. Epigenetics of chronic inflammatory diseases. Journal of Inflammation

518 Research. J Inflamm Res, 2019;12:1-14.

519

5208 Newton K, Dixit, VM. Signaling in innate immunity and inflammation. Cold Spring

$521 \quad$ Harb Perspect Biol, 2012;4:1-19.

522

5239 He P, Jiang T, OuYang X, Liang Y, Zou J, Wang Y, Shen Q, Liao L, Zheng X.

524 Lipoprotein lipase: Biosynthesis, regulatory factors, and its role in atherosclerosis and 525 other diseases. Clin Chim Acta, 2018;480:126-137.

526

$52710 \mathrm{Ma}$ W, Wang Y, Han X, Zhu Y, Liu N. Associations between LPL gene

528 polymorphisms and coronary artery disease: evidence based on an updated and cumulative meta-analysis. Biosci Rep, 2018;38:1-14.

530

53111 Gagné-ouellet V, Houde A, Guay S, Perron P, Gaudet D, Guérin R, Jean-Patrice B,

532 Hivert M, Brisson D, Bouchard L. Placental lipoprotein lipase DNA methylation

533 alterations are associated with gestational diabetes and body composition at 5 years of 534 age. Epigenetics, 2017;12:616-625.

535

53612 Xiao M, Xiao Z. LPL methylation of peripheral blood leukocytes - Prophet of 537 atherothrombotic stroke. Res Sq, 2020:1-15.

538

53913 Shahzad HJ, Babar, H, Shahid MU, Bazai MY, Ali A. Lipoprotein lipase gene

540 polymorphism - Correlation with serum triglycerides levels. Biomedica, 2018;34:81-83. 
54214 Ference BA, Kastelein JJP, Ray KK. Association of Triglyceride-Lowering LPL

543 Variants and LDL-C-Lowering LDLR Variants with Risk of Coronary Heart Disease.

544 JAMA, 2019;321:364-373.

545

54615 Kurylowicz A, Jonas M, Lisik W, Jonas M, Wicik ZA, Wierzbickj Z, Chmura A,

547 Puzianowska-Kuznicka M. Obesity is associated with a decrease in expression but not 548 with the hypermethylation of thermogenesis-related genes in adipose tissues. J Transl 549 Med, 2015;13:1-10.

550

55116 Fenwick PH, Jeejeebhoy K, Dhaliwal R, Royall D, Brauer P, Tremblay A, Klein D, 552 Mucht DM. Lifestyle Genomics and the Metabolic Syndrome: A Review of Genetic

553 Variants that Influence Response to Diet and Exercise Interventions. Food Sci. Nutr, $554 \quad 2019 ; 59: 2028-2039$.

555

55617 Fujimoto Y. Metabolic changes in adipose tissues in response to $\beta 3$-adrenergic

557 receptor activation in mice. J Cell Biochem, 2018;120:1-15.

558

55918 Nonogaki K. New insights into sympathetic regulation of glucose and fat

560 metabolism. Diabetologia, 2000;43:533-549.

561

56219 Lima RPA, Ribeiro MR, Lima KQF, Sena EA, Costa DO, Luna RCP, Nascimento

563 RAF, Gonçalves MCR, Vianna RPT, Moraes RM, Oliveira, NFP, Almeida, ATCA,

564 Costa, MJC. Methylation profile of the ADRB3 gene and its association with lipid

565 profile and nutritional status in adults. Biol Res, 2019;52:1-11.

566 
56720 Yahaya T, Oladele E, Shemichere U, Abdulrau'f M. Role of epigenetics in the

568 pathogenesis and management of type 2 diabetes mellitus. J Med Sci, 2019;6:20-28.

569

57021 Luo Z, Lu Z, Muhammad I, Chen Y, Chen Q, Zhang J, Song Y. Associations of the 571 MTHFR rs1801133 polymorphism with coronary artery disease and lipid levels: a

572 systematic review and updated meta-analysis. Lipids Health Dis, 2018;17:1-15.

573

574

22 Coppedè F. The genetics of folate metabolism and maternal risk of birth of a child

575

with Down syndrome and associated congenital heart defects. Front Genet, 2015;6:1-25.

576

577

23 Bezerra HS, Assis CS, Nunes MKS, Evangelista IWQ, Filho JM, Gomes CNAP, 578

Nascimento RAF, Luna RCP, Costa MJC, Oliveira NFPO, Persuhn DC. The MTHFR

579

promoter hypermethylation pattern associated with the A1298C polymorphism

580

influences lipid parameters and glycemic control in diabetic patients. Diabetol Metab

581

Syndr, 2019;11:1-15.

582

58324 Nunes MKS, Silva AS, Evangelista IWQ, Filho JM, Gomes CNAP, Nascimento

RAFN, Luna RCP, Costa MJC, Oliveira NFP, Persuhn DC. Hypermethylation in the

promoter of the MTHFR gene is associated with diabetic complications and biochemical indicators. Diabetol Metab Syndr, 2017;9:1-9.

587

58825 Coppedè F, Stoccoro A, Tannorella P, Gallo R, Nicolì V, Migliore L. Association of Polymorphisms in Genes Involved in One-Carbon Metabolism with MTHFR Methylation Levels. Int J Mol Sci, 2019;20:1-11. 
26 Costa MJC, Franchescinni S, Diniz SA, Persuhn DC, Lima LEF, Silva A, et al.

593 Segundo ciclo sobre diagnóstico e intervenção da situação alimentar, nutricional,

594 serviços de saúde de doenças não- transmissíveis mais prevalentes da população do

595 município de João Pessoa/PB, 2014/2016.

596

59727 de Oliveira JVB, Lima RPA, Luna RCP, Diniz AS, Almeida ATC, Oliveira NFP,

598 Gonçalves MCR, Lima RT, Ferreira FELL, Diniz SCPOR, Silva AS, Silva AHAE,

599 Persuhn DC, Costa MJC. The direct correlation between oxidative stress and LDL-C

600 levels in adults is maintained by the Friedewald and Martin equations, but the

601 methylation levels in the MTHFR and ADRB3 genes differ. PLoS One., 2020;15:1-18.

602

60328 de Oliveira Y, Lima RPA, Luna RCP, Monteiro MGCA, da Silca CSO, do

604 Nascimento RAF, Lima KQF, Silva AHA, Ferreira FELL, Vianna RPT, Moraes RM,

605 Oliveira NFP, Almeida ATC, Silva AS, Diniz AS, Costa MJC, Gonçalves MCR.

606 Decrease of the DNA methylation level of the ADRB3 gene in leukocytes is related

607 with serum folate in eutrophic adults. J. Transl. Med., 2018;16:1-9.

608

609

29 IBGE. Brazilian Institute of Geography and Statistics. Population count 2010. Rio de

610 Janeiro: Ministry of Planning, 2010.

611

61230 Cochran WG. Sampling Techniques (Walter A. Shewhart). 3rd ed. John Wiley \& 613 Sons;1997.

614

61531 Silva JR, Almeida CD, Guindan JF. Documentary research: theoretical and

616 methodological clues. Brazilian Journal of History and Social Sciences, 2009:1-15. 
61832 World Health Organization. Obesity: preventing and managing the global epidemic.

619 Geneva: Program of Nutrition, Family and Reproductive Health, 1998.

620 https://apps.who.int/iris/handle/10665/63854. Accessed 23 Jun 2021

621

62233 Miller SA, Dykes DD, Polesky HF. A simple salting out procedure for extracting

623 DNA from humam nucleated cells. Nucleic Acids Res., 1988;16:1215.

624

62534 StataCorp. Stata Statistical Software: Release 13. College Station: Stata-

626 Corp LP; 2013.

627

62835 Binnie A, Walsh CJ, Hu P, Dwivedi DJ, Fox-Robichaud A, Liaw PC., Tsang

JLY, Batt J, Carrasqueiro G, Gupta S, Marshall JC, Castelo-Branco P, Santos CC.

630 Epigenetic Profiling in Severe Sepsis: A Pilot Study of DNA Methylation Profiles in

631 Critical Illness. Crit Care Med, 2020;48:1-9.

632

63336 Yousuf FA, Kazmi K, Iqbal J, Ahmed N, Iqbal MP. Higher DNA methylation of

$634 A B O$ gene promoter is associated with acute myocardial infarction in a hospital-based

635 population in Karachi. Pak J Med Sci, 2020;36:505-510.

636

63737 Li X, Wu N, Ji H, Huang Y, Hu H, Li J, Mi S, Duan S, Chen X. A male-specific 638 association between AGTRl hypermethylation and coronary heart disease. Bosn J Basic 639 Med Sci, 2020;20:31-36.

640 
64138 Nehring SM, Goyal A, Bansal P, Patel BC. C Reactive Protein. Stat Pearls. 2020.

642 https://www.ncbi.nlm.nih.gov/books/NBK441843/. Accessed 23 Jun 2021

643

64439 Du Clos TW, Mold C. C-reactive protein: an activator of innate immunity and a

645 modulator of adaptive immunity. Immunol Res, 2004;30:261-77.

646

64740 Sproston NR, Ashworth JJ. Role of C-Reactive Protein at Sites of inflammation and 648 infection. Front Immunol, 2018;9:754-765.

649

65041 Hage FG, Szalai AJ. C-reactive protein gene polymorphisms, C-reactive protein

651 blood levels and cardiovascular disease risk. J Am Coll Cardiol, 2007;50:1115-1122.

652

65342 Drogan D, Boeing H, Janke J, Schmitt B, Zhou Y, Walter J, Pischon T, Tierling S.

654 Regional distribution of body fat in relation to DNA methylation within the $L P L$,

$655 A D I P O Q$ and $P P A R \gamma$ promoters in subcutaneous adipose tissue. Nutr Diabetes,

$656 \quad 2015 ; 5: 1-3$.

657

65843 Arpón A, Santos JL, Milagro FI, Cataldo LR, Bravo C, Riezu-Boi J, Martínez JA.

659 Insulin Sensitivity Is Associated with Lipoprotein Lipase ( $L P L)$ and Catenin Delta 2

660 (CTNND2) DNA Methylation in Peripheral White Blood Cells in Non-Diabetic Young

661 Women. Int J Mol Sci, 2019;20:1-15.

662

66344 Castellano-castillo D, Moreno-Indias I, Fernández-García JC, Alcaide-Torres J,

664 Moreno-Santos I, Ocaña L, Gluckman E, Tinahones F, Queipo-Ortuño MI, Cardona F. 
665 Adipose Tissue LPL Methylation is Associated with Triglyceride Concentrations in the

666 Metabolic Syndrome. Clin Chem, 2018;64:210-218.

667

66845 Myte R, Sundkvist A, Guelpen BV, Harlid S. Circulating levels of inflammatory

669 markers and DNA methylation, an analysis of repeated samples from a population based

670 cohort. Epigenetics, 2019;14:649-659.

671

67246 Walton E, Hemani G, Dehghan A, Relton C, Smith GD. Systematic evaluation of the

673 causal relationship between DNA methylation and C-reactive protein. Biorxiv, 2018:1-

67426.

675

67647 Asllanaj, E, Zhang X, Rosales CO, Nano J, Bramer WM, Portilla-Fernandez E,

677 Braun KE, Gonzalez-Jaramillo V, Ahrens W, Ikram A, Ghanbari M, Voortman T,

678 Franco OH, Muka T, Glisic M. Sexually Dimorphic DNA-methylation in

679 Cardiometabolic Health: A Systematic Review. Maturitas, 2020;135:6-26.

680

68148 Davergarh C, Wedin EH, Broholm C, Henriksen TI, Pedersen M, Pedersen BK,

682 Scheele C, Ling C. Sex influences DNA methylation and gene expression in human

683 skeletal muscle myoblasts and myotubes. Stem Cell Res Ther, 2019;10:1-17.

684

68549 Regitz-zagrosek V, Kararigas G. Mechanistic Pathways of Sex Differences in

686 Cardiovascular Disease. Physiol Rev, 2017;97:1-37.

687 
68850 Braun KVE, Portilla E, Chowdhury R, Nano J, Troup J, Voortman T, Franco OH,

689 Muka T. The Role of Epigenetic Modifications in Cardiometabolic Diseases.

690 Epigenetics of Aging and Longevity, 2018;4:347-364.

691

69251 Zappe K, Pointner A, Switzeny OJ, Magnet U, Tomeva E, Heller J, Mare G, Wagner

693 K, Knasmueller S, Haslberger AG. Counteraction of Oxidative Stress by Vitamin E

694 Affects Epigenetic Regulation by Increasing Global Methylation and Gene Expression

695 of MLH1 and DNMT1 Dose Dependently in Caco-2 Cells. Oxidative Med Cell Longev, 696 2018:1-14.

697

69852 Karmin O, Lynn EG, Chung YH, Siow YL, Man RYK, Choy PC. Homocysteine

699 stimulates the production and secretion of cholesterol in hepatic cells. Biochim

700 Biophys Acta, 1998;1393:317-324.

701

70253 Blasco H, Garcon G, Patin F, Veyrat-Durebex C, Boyer J, Devos D, Vourc'h P,

703 Andres CR, Corcia P. Panel of Oxidative Stress and Inflammatory Biomarkers in ALS:

704 A Pilot Study. Can J Neurol Sci, 2017;44:90-95.

705

70654 Costa-amaral I, Carvalho LVB, Santos MVC, Valente D, Pereira AC, Figueiredo

707 VO, Souza JM, Castro VS, Trancoso MF, Fonseca ASA, Milagres VG, Mendes MPR,

708 Paiva MJN, André LC, Borges RM, Menezes MAC, Alves SR, Gonçalves ES,

709 Sisenando HA, Perini JA, Oliveira MS, Moura-Correa MJ, Teixeira LR, Collins AR,

710 Mattos RCOC, Sarcinelli PN, Larentis AL. Environmental Assessment and Evaluation

711 of Oxidative Stress and Genotoxicity Biomarkers Related to Chronic Occupational

712 Exposure to Benzene. Int. J. Environ. Res. Public Health, 2019;16:2240 - 2272. 
71455 Cui X, Gong J, Han H, He L, Teng Y, Tetley T, Sinharay R, Chung KF, Islam T,

715 Gilliland F, Grady S, Garshick E, Li Z, Zhang J. Relationship between free and total

716 malondialdehyde, a well-established marker of oxidative stress, in various types of

717 human biospecimens. J Thorac Dis 2018;10:3088-3097.

718

71956 Blasco, H, Garcon G, Patin F, Veyrat-Durebex C, Boyer J, Devos D, Vourc'h P, 720 Andres CR, Corcia P. Panel of Oxidative Stress and Inflammatory Biomarkers in ALS:

721 A Pilot Study. Can. J Neurol Sci, 2017;44:90-95.

722

72357 Sayad S, Mahmoudi Z, Ahmadi SAY, Nekouian, R. Comparison of protein-binding

724 malondialdehyde level between breast cancer, fibroadenoma and normal tissues in cases

725 of breast surgery; a pilot study. Ann Res Antioxid, 2019;4:1-4.

726

72758 Bush CJ, Binder CJ. Malondialdehyde epitopes as mediators of sterile inflammation.

728 Biochim Biophys Acta Mol Cell Biol Lipids, 2017;862:398-406.

729

73059 Wang W, Jim H. Homocysteine: A Potential Common Route for Cardiovascular

731 Risk and DNA Methylation in Psoriasis. Chinese Medical Journal, 2017;130:1980 -

7321086.

733

73460 Yang X, Cao R, Yu Y, Sui M, Zhang T, Xu J, Wang X. A study on the correlation

735 between MTHFR promoter methylation and diabetic nephropathy. Am J Transl Res,

$736 \quad 2016 ; 8: 4960-4967$. 
61 Momeni Z, Dehghani A, Fallahzadeh H, Koohgardi M, Dafei M,

739 Hekmatimoghaddam SH, Mohammadi M. The impacts of pill contraceptive low-dose

740 on plasma levels of nitric oxide, homocysteine, and lipid profiles in the exposed vs. non

741 exposed women: as the risk factor for cardiovascular diseases. Contracept Reprod Med, $742 \quad 2020 ; 5: 1-6$.

743

74462 Fallah S, Nouroozi V, Seifi M, Samadikuchaksaraei A, Aghdashi EM. Influence of

745 Oral Contraceptive Pills on Homocysteine and Nitric Oxide Levels: As Risk Factors for

746 Cardiovascular Disease. J Clin Lab Anal, 2012;26:120-123.

747

74863 Grygiel-Górniak B, Ziółkowska-Suchanek I, Kaczmarek E, Mosor M, Nowak J,

749 Puszczewicz M. PPARgamma-2 and ADRB3 polymorphisms in connective tissue

750 diseases and lipid disorders. Clin Interv Aging, 2018;13:463-472.

751

75264 Guay S, Brisson D, Lamarche B, Biron S, Lescelleur O, Biertho SM, Vohl M,

753 Gaudet D, Bouchard L. ADRB3 gene promoter DNA methylation in blood and visceral

754 adipose tissue is associated with metabolic disturbances in men. Epigenomics, $755 \quad 2014 ; 6: 33-43$.

756

75765 Csoka AB, Szyf M. Epigenetic side-effects of common pharmaceuticals: A potential 758 new field in medicine and pharmacology. Medical Hypotheses, 2009;73:770-780.

76066 Akil AA, Jerman LF, Yassin E, Padmajeya SS, Al-Kurbi A, Fakhro KA. Reading

761 between the (Genetic) Lines: How Epigenetics is Unlocking Novel Therapies for Type 1

762 Diabetes. Cells, 2020;9:2403-2417. 
76467 Bridgeman SC, Ellison GC, Melton PM, Newsholme P, Mamotte CDS. Epigenetic

765 effects of metformin: from molecular mechanisms to clinical implications. Diabetes,

766 Obesity and Metabolism, 2018;20:1553-1562.

767

76868 Liu Y, Shen Y, Guo T, Parnell LD, Westerman KE, Smith CE, Ordovas JM, Lai C.

769 Statin Use Associates With Risk of Type 2 Diabetes via Epigenetic Patterns at $A B C G 1$.

$770 \quad$ Frontiers in Genetics, 2020;11:1-11.

771

77269 Andreeva-gateva PA, Mihaleva ID, Dimova II. Type 2 diabetes mellitus and

773 cardiovascular risk; what the pharmacotherapy can change through the epigenetics.

774 Postgraduate Medicine, 2020;132:109-125. 